\title{
The long and winding road
}

\author{
Sergio Dubner ${ }^{1}$, Adrian Baranchuk ${ }^{2}$, Claudio Hadid ${ }^{3}$, Jonathan S. Steinberg ${ }^{4}$, \\ Yunlong Xia ${ }^{5}$, Andrés Ricardo Pérez-Riera ${ }^{6}$ \\ ${ }^{1}$ Arrhythmias and Electrophysiology Service, Clinica y Maternidad Suizo Argentina \\ and De Los Arcos Sanatorio, Buenos Aires, Argentina \\ ${ }^{2}$ Heart Rhythm Service, Kingston General Hospital, Queen's University, Kingston, Ontario, Canada \\ ${ }^{3}$ Cardiology Service, Hospital Cosme Argerich, Buenos Aires, Argentina \\ ${ }^{4}$ Valley Health System and Mt. Sinai School of Medicine, New York, NY, USA \\ ${ }^{5}$ Department of Cardiology, First Affiliated Hospital of Dalian Medical University, Dalian, China \\ ${ }^{6} \mathrm{ABC}$ 's Faculty of Medicine, ABC Foundation, Cardiology Discipline, Electrovectorcardiogram Sector, \\ Santo André, Sao Paulo, Brazil
}

We chose the title "The long and winding boad", a beautiful song from "The Beatles" [1] for many different reasons. First, the road that the Cardiology Journal took in the last years to arrive at the current stage was a long road, often winding (sometimes not easy to walk it!), and we are traveling on this interesting journey. Second, "The Beatles" are one of the international/universal rock bands that reflect on how the world became smaller. We can all relate to and enjoy their music, and even when the meaning of their songs would be different for different people around the world, the joy persists.

This was the vision of our predecessors that decided to take Cardiology Journal to an international level, increasing the visibility of this journal, allowing this journal to be read and enjoyed by people from all around the world.

This year was not the exception for this arduous expedition. After a smooth transition with the previous Editor-in-Chief, Prof. Wojciech Zareba, we started working with a new editorial team and a new web system, and although we left many intact, new ideas were included.

Rather than an Editor-in-Chief solely at the helm, an editorial team was created, with monthly web-meetings to discuss current issues and future trends. This activity generated valuable feedback that allowed the group to evaluate submitted papers reducing the number of manuscripts sent to the reviewers.
We are planning on new interactions with the reviewers to make their work easier and more efficient, such as free subscription for a year at any time that they review a paper for the journal and a list of similar papers previously published in Cardiology Journal.

One of the major achievements in the last months was the DOI number and the ahead of print publication that significantly reduced the time between acceptance and final publication. This allows the authors to reference their article at the time that DOI is adjudicated.

The journal became more international and this is reflected by the fact that we are receiving articles from different countries around the world. Major contributions came from Poland, of course, but similar burden came from Turkey and China as well. Many others countries from Europe as well as the US increased their submission numbers. The visibility of the journal also increased in South America.

Educational agreements were performed with several national and international societies such as the Argentine Federation of Cardiology, The Uruguayan Society of Cardiology, SOLACI (Latin American Society for Interventional Cardiology) and SOLAECE (Latin American Society of Arrhythmias and Cardiac Stimulation) with a very interesting exchange. All the delegates from those societies have free access to Cardiology Journal and on the other hand, some members related to the 
societies' journals, are working closer with us and some national guidelines are ready to be published in our journal. These agreements will increase the chances to exchange experiences with colleagues from other parts of the world.

Something that we would like to highlight is the number and high scientific quality of some Editorial comments that we have received the last year. Prof. Moss' editorial on primary prevention of sudden cardiac death [2] was one of the most frequently downloaded manuscripts this year. Dr Moss summarized the MADIT family trials and the impact of primary prevention ICD implant on sudden cardiac death. Dr Cocco published a review article on a rare disease, Behcet disease [3] that was referenced by other authors on several occasions during this year. Dr Fisman, current Editor-in-Chief of Cardiac Diabetology, wrote an interesting editorial regarding metabolic syndrome and the analysis of four conditions: obesity, dyslipemia, hypertension and glucose intolerance [4].

The original article by Pytkowski et al. [5] presented the highest impact on the topic of arrhythmias with a novel algorithm for focus localization in patients with right ventricular outflow tract arrhythmias, a useful observation to obtain better results with radiofrequency ablation.

Currently, a large number of papers are received every day, and despite their high quality, exceed our chances for publication. Accordingly, our rejection rate has increased and there are many papers that do not achieve high priority for publication. We would prefer to publish all submitted articles, but this is impossible in an international journal. The good side of this is that higher quality papers get published with will favorably affect our Impact Factor.

The increased visibility of Cardiology Journal was also shared by another journal of the same publisher, Kardiologia Polska. In fact, both of them grew up significantly during the last year. The paper submitted by Rosiak et al. [6] regarding the effect of doubling the dose of acetylsalicylic in patients with type 2 diabetes was extremely popular within the cardiology community as well as the original paper from Erdogan et al. [7] on slow coronary flow phenomenon, which was the most read paper in Kardiologia Polska.

In summary, Cardiology Journal is walking this long and winding road with increasing confidence and certitude about its mission. We are focused towards 2014 when most of our ideas and new activities will be reflected in higher quality, visibility and scientific impact.

We would like to encourage you to submit your work to Cardiology Journal. We are committed to a fair, high quality review and expedited turnaround, to make the experience of publishing in Cardiology Journal, a very good one.

\section{Conflict of interest: none declared}

\section{References}

1. Lennon J, McCartney P. The long and winding road. Recorded January $31^{\text {st }}, 1969$ Apple Studios, Published May $8^{\text {th }}, 1970$.

2. Moss AJ. Saving lives and reducing inappropriate device therapy: The MADIT family of implantable cardioverter-defibrillator and cardiac resynchronization therapy trials. Cardiol J, 2013: 20: 217-219.

3. Cocco G, Jerie P. A review. cardiac pathology and modern therapeutic approach in behçet disease. Cardiol J, AOP. DOI: 10.5603/ /CJ.a2013.0056.

4. Fisman T, Tenenbaum A. The metabolic syndrome entanglement: Cutting the Gordian knot. Cardiol J, AOP. DOI: 10.5603/ /CJ.a2013.0054.

5. Pytkowski M, Maciag A, Sterlinski M et al. Novel algorithm for arrhythmogenic focus localization in patients with right ventricular outflow tract arrhythmias. Cardiol J, AOP. DOI: 10.5603/ /CJ.a2013.0111.

6. Rosiak M, Postula M, Kapłon-Cieślicka A et al. The effect of doubling the dose of acetylsalicylic acid (ASA) on platelet function parameters in patients with type 2 diabetes and platelet hyperreactivity during treatment with $75 \mathrm{mg}$ of ASA: A subanalysis of the AVOCADO study. Kardiol Pol, 2013; 71: 552-557.

7. Erdogan T, Canga A, Altan Kocaman S et al. Increased epicardial adipose tissue in patients with slow coronary flow phenomenon. Kardiol Pol, 2012; 70: 903-909. 